\title{
CBN-19-93 Bartesaghi
}

Case Report

MS, 1 figure, 1 table

\section{Psychiatric Disorders in Alzheimer Disease With the Presenilin-1 L226F Mutation}

\author{
Francesca Bartesaghi, MD, ${ }^{*}+$ Chiara Emilia Rosci, MD, ${ }^{*}+$ Cecilia Rassiga, ${ }^{*}+$ Valentina \\ Barbieri, MD, * $\neq$ Orsola Gambini, MD, * $\neq$ Stefano Floro, MD, *† Andrea Maria D’Arrigo,

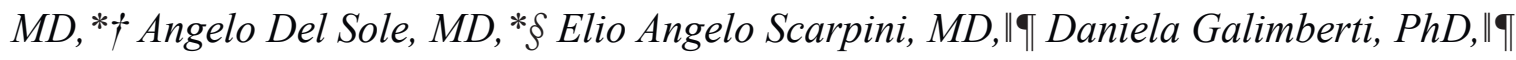 \\ and Alberto Priori, $M D, P h D^{* \dagger}$
}

From the *Aldo Ravelli Center for Neurotechnology and Experimental Neurotherapeutics, University of Milan, Milan, Italy; †Clinical Neurology Unit I, ASST Santi Paolo e Carlo, Department of Health Sciences, University of Milan, San Paolo University Hospital, Milan, Italy; †Clinical Psychiatry Unit, ASST Santi Paolo e Carlo, Department of Health Sciences, University of Milan, San Paolo University Hospital, Milan, Italy; §Nuclear Medicine Unit, ASST Santi Paolo e Carlo, Department of Health Sciences, University of Milan, San Paolo University Hospital, Milan, Italy; ॥University of Milan, Dino Ferrari Center, Milan, Italy; and \Neurodegenerative Diseases Unit, Fondazione IRCCS Cà Granda, Ospedale Maggiore Policlinico, Milan, Italy.

Portions of this work were presented at the annual meeting of the Italian Society of Neurology-Dementia, April 8, 2019, in Florence, Italy. 
[Corresponding author: Alberto Priori, MD, Clinica Neurologica Università degli Studi di Milano, Polo Universitario San Paolo, Via Antonio di Rudinì 8, Milano 20100 Italy; Telephone number: 0281843 225. email address: alberto.priori@unimi.it]

The authors declare no conflicts of interest.

Correspondence: Alberto Priori, MD, PhD, Neurology Unit, University of Milan, San Paolo University Hospital, Antonio di Rudinì 8 Street, Milan 20100 Italy (email: alberto.priori@unimi.it).

Running head: Psychiatry of Presenilin-1 L226F Mutation

\begin{abstract}
The presenilin-1 (PSEN1) L226F mutation has been linked to very early onset of prominent behavioral and psychiatric disturbances followed by cognitive decline within a few years. We report a novel case of early-onset Alzheimer disease that was originally diagnosed as psychotic depression in a patient with this gene mutation. We also compare our patient's clinical data to those of other cases of this mutation that have been described in the literature. Because atypical behavioral and psychiatric disturbances in young ( $<40$ years) individuals can herald Alzheimer disease, a tight collaboration between psychiatrists and neurologists is crucial for an early diagnosis.
\end{abstract}


Key Words: early-onset Alzheimer disease, PSEN1, genetic, behavioral symptoms

\begin{abstract}
$\mathbf{A D}=$ Alzheimer disease. ADAD $=$ autosomal dominant Alzheimer disease. PSEN1 = presenilin-1.
\end{abstract}

Genetic mutations in the presenilin-1 (PSEN1) gene are the most common cause of autosomal dominant Alzheimer disease (ADAD) (Lleò et al, 2004). The manifestation of ADAD may sometimes be difficult to recognize, particularly if the patient presents with early-onset psychiatric disturbances. A classical neurologic condition such as Alzheimer disease (AD) may present with initial psychiatric features such as depression or bipolar disorder; however, detection of a neurologic substrate underlying the early phases of ADAD, especially when psychiatric features are prominent in young ( $<40$ years) individuals, remains unclear. In this report, we present a case of ADAD with the rare PSEN1 L226F mutation. We also review the only other three cases of ADAD with the PSEN1 L226F mutation that have been reported thus far.

PSEN1 L226F is a very rare gene mutation and has been reported in only three prior cases (Bagyinszky et al, 2016; Gómez-Tortosa et al, 2010; Zekanowski et al, 2006). First detected in 2006, PSEN1 L226F is a missense point mutation on exon 7 of chromosome 14 $(\mathrm{CTC} \rightarrow \mathrm{TTC})$ that results in the substitution of leucine with phenylalanine, which causes changes in the surface of a transmembrane domain of PSEN1 by increasing hydrophobic interactions. The first case of an individual with this gene mutation was a man with prominent behavioral symptoms who had been clinically diagnosed with frontotemporal dementia at the age of 33 (Zekanowski et al, 2006). His autopsy revealed AD pathology. The second case was a 33-year-old woman who had developed depression followed by a speech 
and memory deficit; she was clinically diagnosed with $\mathrm{AD}$, which was confirmed at autopsy (Gómez-Tortosa et al, 2010). The third case was a 37-year-old woman who had developed paranoid ideation and anxiety, which progressed to nonfluent aphasia and cognitive and memory deficits; she was clinically diagnosed with $\mathrm{AD}$, but no autopsy was performed (Bagyinszky et al, 2016).

These three cases, plus the one presented here, had a prodromal phase that was dominated by isolated psychiatric disturbances that occurred while the patients were in their early 30s; this phase was followed by rapid cognitive decline and dementia.

\section{CASE REPORT}

A 36-year-old, left-handed woman of South American origin was referred to the neurology department of the Aldo Ravelli Center for Neurotechnology and Experimental Neurotherapeutics in Milan, Italy, in the spring of 2018 with a history of behavioral changes and cognitive impairment that had begun 8 years earlier. The first manifestations of affective restriction were noticed by her family in 2010, but it was not until 2012, after her last child was born, that the woman consulted a psychiatrist. At that time, she was diagnosed with postpartum depression with psychotic symptoms and was treated with antipsychotic medication and antidepressants.

Despite the treatment, the patient reported that she had never completely recovered from her psychotic symptoms; nevertheless, she spontaneously stopped taking her medications soon after 2012 until 2017. Her family members stated that during this time, the patient experienced vague cognitive manifestations, such as forgetfulness and anxiety, which they ascribed to her personality. The patient and her family moved abroad from 2015 to 2017 to manage a new commercial activity but returned to Italy due to the patient's growing inability to manage money and activities of daily living. Her clinical picture consisted of severe anxiety with frequent bursts of tears, interpretative thinking toward her family 
members, disorganization, and forgetfulness. During the past year, she had become totally incapable of taking care of herself and her three children. Moreover, her family members reported at least one episode of spatial disorientation where the patient was unable to find her way home. In the autumn of 2017, her family asked for a psychiatric re-evaluation.

At the beginning of 2018, the patient met with a private psychiatrist who prescribed aripiprazole and escitalopram for a "dissociative picture with depressive elements." She was admitted to the psychiatry ward of our hospital, where duloxetine was introduced to manage her depression. Because of her extrapyramidal symptoms, aripiprazole was replaced with olanzapine. These medications were effective in reducing the patient's anxiety and akathisia but had no beneficial effect on her cognition. In addition, during hospitalization, the psychiatrist observed compulsive behavior and a lack of inhibition.

In the spring of 2018, the patient was assessed by a neurologist, an expert in dementia, who suspected that she had a neurologic, rather than a psychiatric, condition. The patient was transferred to the neurology department of the Aldo Ravelli Center for Neurotechnology and Experimental Neurotherapeutics in Milan, Italy, for further diagnostic tests and therapeutic management.

The patient's family history was unknown because she had been adopted, but she stated that she had experienced normal early development. However, the family reported that she had a history of occasional drug and alcohol abuse during adolescence and young adulthood.

\section{ASSESSMENTS}

We performed complete neurologic and neuropsychological examinations using tests that explore executive, attention, memory, and language functions. Blood tests were also performed, complete with a screening for autoimmune and infective diseases; cerebrospinal fluid dosage of beta-amyloid, tau, and phosphorilated tau; and a neuroradiological study with 
MRI, followed by ${ }^{18}$ F-FDG-PET and florbetaben-PET. To confirm our suspicion of a neurodegenerative condition, we performed genetic testing using next-generation sequencing. We administered quetiapine and pregabalin to manage the patient's behavioral symptoms and rivastigmine to manage her cognitive function. At the 6-month follow-up, we retested her with the same battery of neuropsychological tests.

\section{RESULTS}

\section{Neurologic and Neuropsychological Examinations}

Cognitive functions aside, the patient's neurologic examination was unremarkable. Quetiapine and pregabalin were effective in reducing her anxiety and her psychotic symptoms. The neuropsychological assessment, however, showed severe, multidomain cognitive impairment characterized by temporospatial disorientation, recent and remote memory impairment, attention deficit, naming deficit with anomia and semantic errors, reduced semantic and phonemic verbal fluency, visuospatial impairment (constructional apraxia with closing in), and symmetric ideomotor apraxia. She scored 12 out of 30 on the Mini-Mental State Examination, indicating severe cognitive impairment (Measso et al, 1993. Overall, the patient's neuropsychological data were compatible with AD.

\section{Blood Tests}

The patient's blood tests were normal. Serological testing ruled out syphilis and viral infections, including HIV. Cerebrospinal fluid analysis was consistent for reduced levels of beta-amyloid ( $536 \mathrm{pg} / \mathrm{ml}$, cutoff level $>600 \mathrm{pg} / \mathrm{ml})$ and for elevated levels of the tau (1603 $\mathrm{pg} / \mathrm{ml}$, cutoff level $<300 \mathrm{pg} / \mathrm{ml}$ ) and phosphorilated tau proteins (133 pg/ml, cutoff level $<61$ $\mathrm{pg} / \mathrm{ml})$. Her anti-NMDA antibodies were negative. 


\section{Radiologic Findings}

MRI showed temporoparietal and bilateral hippocampal atrophy $\left(1.4 \mathrm{~cm}^{3}\right.$ bilaterally $)$

(Figure 1A). FDG-PET revealed bilateral hypometabolism of the precuneus, posterior cingulate, temporoparietal, and frontal areas (Figure 1B). Florbetaben-PET demonstrated diffuse increase of cortical uptake and an intense uptake in the basal ganglia (Figure 1C).

$<$ Insert Figure 1 here $>$

\section{Genetic Testing}

Despite the relatively young age of our patient at symptom onset, her neuropsychological test results, supported by her FDG-PET and florbetaben-PET results, prompted us to test for genetic mutations linked to dementia. Genetic screening revealed the presence of the PSEN1 L226F mutation. The patient's apolipoprotein E genotype was E3/E3. At this point, we made the diagnosis of ADAD.

We administered rivastigmine, which is the first-line therapy choice for such cases (up to $9.5 \mathrm{mh} / 24 \mathrm{~h}$ ), but after a transient improvement in attention and orientation, the patient's cognitive function worsened, as repetition of the neuropsychological tests demonstrated at the 6-month follow-up, with a loss of function in everyday activities. At the 18-month follow-up, the patient's cognitive decline had further progressed to complete dependency in all daily activities in addition to insomnia and language and comprehension deterioration. Seizures appeared at about the same time, requiring the introduction of lamotrigine. We observed no further motor or sensory impairment.

At the end of 2019, the patient was institutionalized in a health care facility, where she died at the beginning of 2020. An autopsy was not performed. 
Our case involved a young woman with behavioral abnormalities followed by a clinical picture mimicking postpartum psychiatric disturbances, who, within 5 years of the first behavioral symptoms, demonstrated progressive cognitive impairment that eventually led to complete dependency. To date, this is the most extensively studied individual carrying the PSEN1 L226F mutation.

The clinical presentation of ADAD caused by PSEN1 mutations can be similar to that of the sporadic form of $\mathrm{AD}$, with the amnestic presentation being the most frequent. Neurologic features such as myoclonus, seizures, and extrapyramidal and cerebellar signs are more frequent in the autosomal dominant form of $\mathrm{AD}$ than in the sporadic form (Ringman et al, 2014). Atypical language and behavioral presentations can occur in a minority of both autosomal dominant and sporadic cases (Bateman et al, 2011). Spastic paraparesis and pyramidal signs can also occur in individuals with PSEN1 mutations (Karlstrom et al, 2008).

Evidence of the association between PSENI mutations and frontotemporal dementialike phenotypes has been reported (Blauwendraat et al, 2018), but very few reports exist (Raux et al, 2000; Riudavets et al, 2013). The main consideration arising from our case and the three previously reported cases is that the PSEN1 L226F mutation was heralded by atypical psychiatric disturbances followed by cognitive decline within a few years. All four individuals were diagnosed in their 30 s, and their cognitive decline caused language impairment and behavioral changes. No extrapyramidal signs were present in our patient, but parkinsonism may be a late feature of ADAD related to the PSEN1 L226F mutation (Table 1). 
Most of the variance between different PSEN1 mutations in age at symptom onset seems to be accounted for by ADAD mutation, even if some clinical variability remains within many families with the same mutation. This finding suggests that other factors may have a role in modifying the onset of symptoms (Ryman et al, 2014). Nonetheless, age at symptom onset, clinical presentation, and disease progression seem to present a consistent picture of PSEN1 L226F mutation, regardless of the ethnic or environmental background of the individuals.

Even though our patient started developing the first symptoms of $\mathrm{AD}$ in her late 20s, many years passed between the time when she experienced the first behavioral changes and the time at which she lost her autonomy due to cognitive impairment. A long initial phase during which psychiatric disturbances dominate the clinical picture appears to be a shared feature of our case and the other three cases of PSEN1 L226F mutation.

The core diagnostic criteria for $\mathrm{AD}$ remain clinical; however, the recently revised criteria recognize the importance of other diagnostic methods beyond genetic testing, such as using neuroimaging (MRI, FDG-PET, amyloid-PET) and cerebrospinal fluid (beta-amyloid, tau, and phosphorylated tau) biomarkers, which can increase or decrease the level of certainty that AD pathology underlies the dementia (Jack et al, 2011).

Our patient's brain MRI and FDG-PET are in line with the data that have been reported in the literature. For example, in an MRI volumetric study, Gosche et al (2002) showed hippocampal atrophy, and Um et al (2017) demonstrated severe, diffuse cortical hypometabolism on FDG-PET. An amyloid-PET scan is indicated in individuals with progressive mild cognitive impairment with an uncertain etiology, individuals with atypical presentations and clinical course, and individuals with early-onset progressive dementias (Johnson et al, 2013).

Individuals with early-onset $\mathrm{AD}$ may have a different topography of amyloid deposition compared to those with late-onset AD. For example, individuals with early-onset 
$\mathrm{AD}$ retain higher levels of $\mathrm{PiB}$ (Pittsburgh $\mathrm{B}$ compound) in the bilateral basal ganglia, bilateral thalamus, left superior temporal cortex, and left cuneus compared to those with lateonset AD (Cho et al, 2013). More specifically, amyloid deposition appears to begin in the striatum of PSEN1 mutation carriers, whereas the earliest deposition in individuals with sporadic $\mathrm{AD}$ appears to be in the frontal cortex and the precuneus/posterior cingulate region (Klunk et al, 2007). Florbetaben-PET in our patient demonstrated a diffuse cortical uptake and, despite the absence of extrapyramidal motor disturbances, an intense uptake in the basal ganglia, as described in individuals with early-onset AD (Cho et al, 2013; Um et al, 2017).

\section{CONCLUSION}

Our report describes a rare case of PSEN1 L226F mutation and early-onset ADAD. Our case aligns with the distinctive phenotype of the mutation-young prodromal psychiatric presentation followed by cognitive decline - similarly to the other three cases available in the literature. ADAD can hide behind insidious atypical psychiatric disturbances, which should be diagnostically assessed in tight collaboration between psychiatrists and neurologists. The behavioral and psychiatric disturbances exhibited by individuals with ADAD are the same as those often found in individuals with the prefrontal syndromes. A careful neurologic assessment should search for other subtle signs of frontal lobe and cognitive dysfunction that will lead to a diagnosis of ADAD. 


\section{REFERENCES}

Bagyinszky E, Park SA, Kim HJ, et al. 2016. PSEN1 L226F mutation in a patient with earlyonset Alzheimer's disease in Korea. Clin Interv Aging. 11:1433-1440. doi:10.2147/CIA.S111821

Bateman RJ, Aisen PS, De Strooper B, et al. 2011. Autosomal-dominant Alzheimer's disease: a review and proposal for the prevention of Alzheimer's disease. Alzheimers Res Ther. 3:1. doi:10.1186/alzrt59

Blauwendraat C, Wilke C, Simón-Sánchez J, et al. 2018. The wide genetic landscape of clinical frontotemporal dementia: systematic combined sequencing of 121 consecutive subjects. Genet Med. 20:240-249. doi:10.1038/gim.2017.102

Cho H, Seo SW, Kim J-H, et al. 2013. Amyloid deposition in early onset versus late onset Alzheimer's disease. J Alzheimers Dis. 35:813-821. doi:10.3233/JAD-121927

Gómez-Tortosa E, Barquero S, Barón M, et al. 2010. Clinical-genetic correlations in familial Alzheimer's disease caused by presenilin 1 mutations. J Alzheimers Dis. 19:873-884. doi:10.3233/JAD-2010-1292

Gosche KM, Mortimer JA, Smith CD, et al. 2002. Hippocampal volume as an index of Alzheimer neuropathology: findings from the Nun study. Neurology. 58:1476-1482. doi:10.1212/wnl.58.10.1476

Jack CR Jr, Albert M, Knopman DS, et al. 2011. Introduction to Revised Criteria for the Diagnosis of Alzheimer's Disease: National Institute on Aging and the Alzheimer Association Workgroups. Alzheimers Dement. 7:257-262. doi:10.1016/j.jalz.2011.03.004

Johnson KA, Minoshima S, Bohnen NI, et al. 2013. Appropriate use criteria for amyloid PET: a report of the Amyloid Imaging Task Force, the Society of Nuclear Medicine 
and Molecular Imaging, and the Alzheimer's Association. J Nucl Med. 54:476-490. doi:10.2967/jnumed.113.120618

Karlstrom H, Brooks WS, Kwok JB, et al. 2008. Variable phenotype of Alzheimer's disease with spastic paraparesis. $J$ Neurochem. 104:573-583. doi:10.1111/j.14714159.2007.05038.x

Klunk WE, Price JC, Mathis CA, et al. 2007. Amyloid deposition begins in the striatum of presenilin-1 mutation carriers from two unrelated pedigrees. J Neurosci. 27:61746184. doi:10.1523/JNEUROSCI.0730-07.2007

Lleò A, Berezovska O, Growdon JH, et al. 2004. Clinical, pathological, and biochemical spectrum of Alzheimer disease associated with PS-1 mutations. Am J Geriatr Psychiatry. 12:146-156.

Measso G, Cavarzeran F, Zappalà G, et al. 1993. The Mini-Mental State Examination: normative study of an Italian random sample. Dev Neuropsychol. 9:77-85. doi:10.1080/87565649109540545

Raux G, Gantier R, Thomas-Anterion C, et al. 2000. Dementia with prominent frontotemporal features associated with L113P presenilin 1 mutation. Neurology. 55:1577-1578. doi:10.1212/wnl.55.10.1577

Ringman JM, Goate A, Masters CL, et al. 2014. Genetic heterogeneity in Alzheimer disease and implications for treatment strategies. Curr Neurol Neurosci Rep. 14:499. doi:10.1007/s11910-014-0499-8

Riudavets MA, Bartoloni L, Troncoso JC, et al. 2013. Familial dementia with frontotemporal features associated with M146V presenilin-1 mutation. Brain Pathol. 23:595-600. doi:10.1111/bpa.12051

Ryman DC, Acosta-Baena N, Aisen PS, et al. 2014. Symptom onset in autosomal dominant Alzheimer disease: a systematic review and meta-analysis. Neurology. 83:253-260. doi:10.1212/WNL.0000000000000596 
Um YH, Choi WH, Jung WS, et al. 2017. A case report of a 37-year-old Alzheimer's disease patient with prominent striatum amyloid retention. Psychiatry Investig. 14:521-524. doi:10.4306/pi.2017.14.4.521

Zekanowski C, Golan MP, Krzyśko KA, et al. 2006. Two novel presenilin 1 gene mutations connected with frontotemporal dementia-like clinical phenotype: genetic and bioinformatic assessment. Exp Neurol. 200:82-88.

doi:10.1016/j.expneurol.2006.01.022 


\section{Figure Legend}

FIGURE 1. A. MRI of the brain, FLAIR sequences: (1) coronal section; (2) axial section: note the temporoparietal and hippocampal atrophy (arrows). B. FDG-PET of the brain, 3D reconstruction of transaxial sections, qualitative study: (1) right hemisphere, lateral view; (2) left hemisphere, lateral view; (3) right hemisphere, medial view; (4) left hemisphere, medial view; note the bilateral hypometabolism (green-blue) of the precuneus, posterior cingulate, temporoparietal, and frontal areas (arrows). C. Florbetaben-PET of the brain, 3D reconstruction of transaxial sections, qualitative study: (1) right hemisphere, lateral view; (2) left hemisphere, lateral view; (3) anterior view; (4) posterior view; $(5,6)$ axial sections; note the diffuse increase of cortical uptake of the tracer (red), demonstrating cortical deposition of beta-amyloid and an intense uptake in the basal ganglia. Our case is the first where an amyloid-PET scan was performed, further confirming that the PSEN1 L226F mutation is associated with the particular deposition pattern (arrows). 
TABLE 1. Clinical Features of Individuals With the Presenilin-1 L226F Mutation

\begin{tabular}{|c|c|c|c|c|}
\hline Feature & $\begin{array}{l}\text { Zekanowski et } \\
\text { al, } 2006\end{array}$ & $\begin{array}{l}\text { Gómez-Tortosa et } \\
\text { al, } 2010\end{array}$ & $\begin{array}{l}\text { Bagyinszky et al, } \\
2016\end{array}$ & Our Case \\
\hline Gender & Male & Female & Female & Female \\
\hline $\begin{array}{l}\text { Age at diagnosis } \\
\text { (years) }\end{array}$ & 33 & 33 & 37 & 36 \\
\hline Family history & $\begin{array}{l}\text { Mother, early } \\
\text { dementia ( } 33 \\
\text { years) }\end{array}$ & $\begin{array}{l}\text { Father, early } \\
\text { dementia ( } 36 \\
\text { years) }\end{array}$ & None & Unknown \\
\hline Clinical diagnosis & FTD & $\mathrm{AD}$ & $\mathrm{AD}$ & $\mathrm{AD}$ \\
\hline Symptoms & $\begin{array}{l}\text { Behavioral } \\
\text { changes, frontal } \\
\text { signs, subsequent } \\
\text { severe memory } \\
\text { impairment, } \\
\text { parkinsonism, } \\
\text { and mutism }\end{array}$ & $\begin{array}{l}\text { Depression, } \\
\text { dysarthria and } \\
\text { nonfluent aphasia, } \\
\text { cognitive } \\
\text { impairment, and } \\
\text { parkinsonism }\end{array}$ & $\begin{array}{l}\text { Paranoid ideation } \\
\text { and anxiety, } \\
\text { cognitive decline, } \\
\text { frontal signs, } \\
\text { nonfluent aphasia, } \\
\text { mutism, and } \\
\text { parkinsonism }\end{array}$ & $\begin{array}{l}\text { Psychotic } \\
\text { depression, } \\
\text { cognitive decline } \\
\text { with marked } \\
\text { memory and } \\
\text { language deficit, } \\
\text { and seizures }\end{array}$ \\
\hline $\begin{array}{l}\text { Neuropsychological } \\
\text { examination }\end{array}$ & $\begin{array}{l}\text { Impairment in } \\
\text { planning, } \\
\text { problem solving, } \\
\text { and attention }\end{array}$ & $\begin{array}{l}\text { Deficit in verbal } \\
\text { memory and in } \\
\text { executive and } \\
\text { visuoconstructive } \\
\text { functions }\end{array}$ & $\begin{array}{l}\text { Deficit in } \\
\text { calculation, praxis, } \\
\text { visuoconstructive } \\
\text { function, and } \\
\text { memory }\end{array}$ & $\begin{array}{l}\text { Attention deficit, } \\
\text { language deficit } \\
\text { with anomia and } \\
\text { reduced semantic } \\
\text { and verbal } \\
\text { fluency, } \\
\text { constructional } \\
\text { apraxia with } \\
\text { closing in, and } \\
\text { ideomotor apraxia }\end{array}$ \\
\hline Neuroimaging & $\begin{array}{l}\text { CT: frontal } \\
\text { atrophy } \\
\text { SPECT: frontal } \\
\text { areas } \\
\text { hypoperfusion }\end{array}$ & $\begin{array}{l}\text { MRI: mainly } \\
\text { biparietal atrophy }\end{array}$ & $\begin{array}{l}\text { MRI: bilateral } \\
\text { hippocampal and } \\
\text { parietal cortical } \\
\text { atrophy } \\
\text { FDG-PET: mainly } \\
\text { biparietal } \\
\text { hypometabolism }\end{array}$ & $\begin{array}{l}\text { FDG-PET: } \\
\text { temporoparietal } \\
\text { and frontal } \\
\text { hypometabolism } \\
\text { Amyloid-PET: } \\
\text { diffuse cortical } \\
\text { uptake, in } \\
\text { particular in the } \\
\text { basal ganglia }\end{array}$ \\
\hline Age at death & 38 & 42 & 44 & 38 \\
\hline Autopsy & AD pathology & AD pathology & Not done & Not done \\
\hline
\end{tabular}


$\mathbf{A D}=$ Alzheimer disease. FTD $=$ frontotemporal dementia. $\mathbf{S P E C T}=$ single-photon emission computed tomography. 


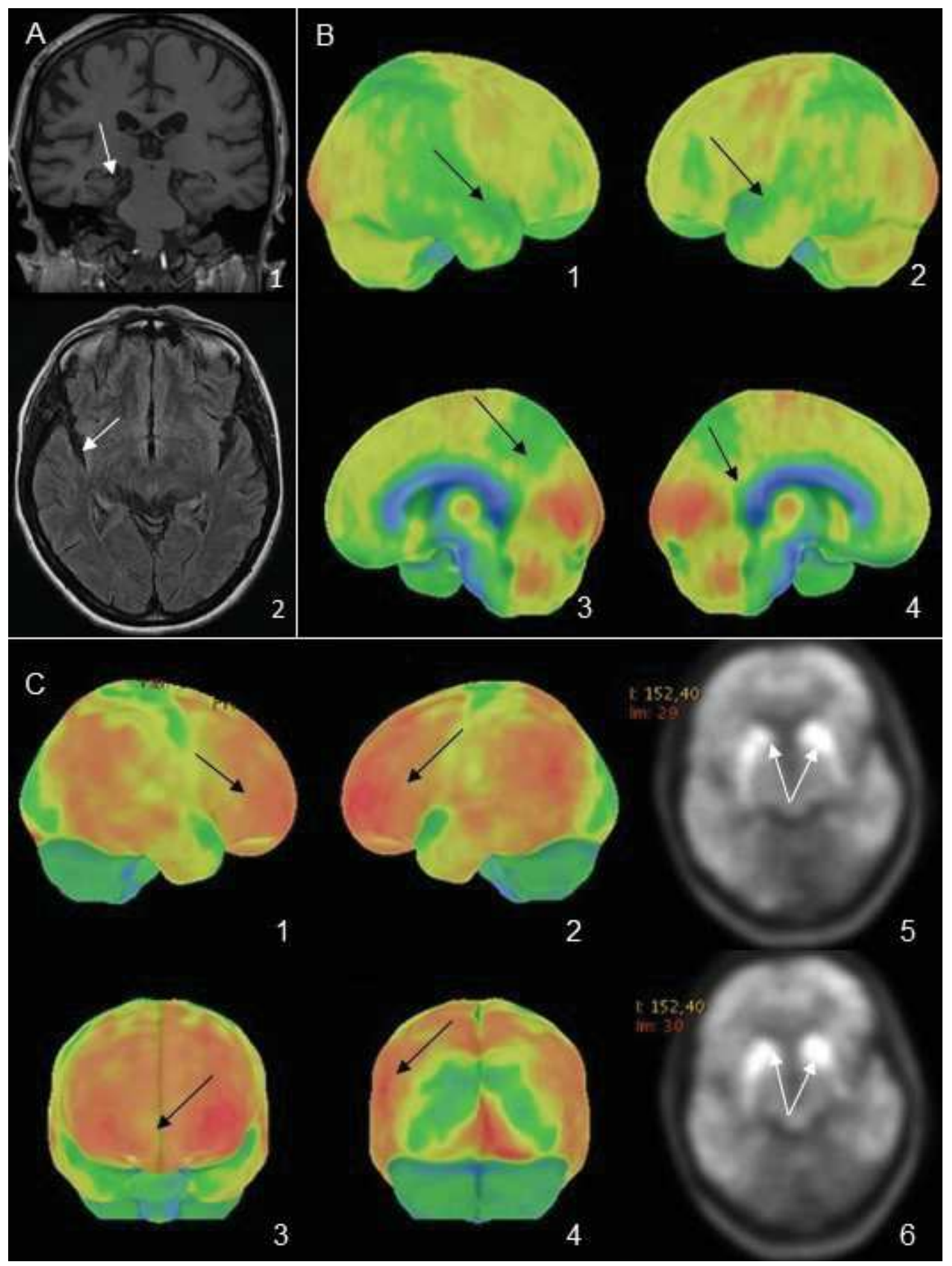

